\title{
Thinking of the Textbook in the ESL/EFL Classroom
}

\author{
Wang Wen-Cheng \\ Department of Business Management, \\ Hwa Hsia Institute of Technology, Taiwan \\ 111 Gong Jhuan Rd., Chung Ho, Taipei, Taiwan, R.O.C \\ Tel: 886-2-89415022Ｅ-mail: wcwang@cc.hwh.edu.tw \\ Lin Chien-Hung \\ Department of Business Management, \\ Hwa Hsia Institute of Technology, Taiwan \\ 111 Gong Jhuan Rd., Chung Ho, Taipei, Taiwan, R.O.C \\ Tel: 886-2-89415022Ｅ-mail: davidamy22@yahoo.com.tw \\ Lee Chung-Chieh \\ Department of Senior Citizen Service Management \\ Chia Nan University of Pharmacy \& Science, Tainan, Taiwan, R.O.C \\ Tel: 886-6-2664911Ｅ-mail: suprapeter1970@yahoo.com.tw
}

Received: October 25, 2010 Accepted: December 10, 2010 doi:10.5539/elt.v4n2p91

\begin{abstract}
Textbooks provide novice teachers with guidance in course and activity design; it assures a measure of structure, consistency, and logical progression in a class; It meets a learner's needs or expectations of having something concrete to work from and take home for further study; It may provide multiple resources: tapes, CDs, videos, self-study workbooks etc. While the quality of ESL reading textbooks has improved dramatically in recent years, the process of selecting an appropriate text has not become any easier for most teachers and administrators. Thus, the paper discusses for evaluating reading textbooks for use in ESL/EFL classrooms. Classroom teachers spend much time using textbooks in class, so choosing an appropriate one is important. And the paper describes the role of the textbook. Using this will make the textbook selection process more efficient and more reliable.
\end{abstract}

Keywords: Textbook, ESL, EFL, Teacher, Classroom

\section{Background}

Textbooks and related teaching and learning materials/media have been adapted continuously to the ever-changing and growing challenges and demands of learning English as a foreign language, to new findings in foreign/second language research and theory construction and to advances in information technology, scholarly views on the role of the textbook and recommendations on how to use it in everyday classroom practice very often reflect little more than personal opinion and/or common sense. Learning is simply the process of adjusting the environment to accommodate new experiences. The administrative de-emphasis of the teacher in the second language classroom would suggest that teachers must learn how to integrate and organize content of a textbook to make learning an interactive and meaningful experience, as opposed to an act that can be completed alone by self-directed study with a textbook. A practical, thorough, and straightforward method for choosing ESL textbooks is to analyze the options according to program issues, going from broad to specific. The strategy behind this technique is to eliminate unsatisfactory textbooks at each stage of analysis so that only the most appropriate are left at the end, making the choice clear and manageable. Parrish (2004) describes benefits of using a textbook can meet a learner's needs or expectations of having something concrete to work from and take home for further study.

While the quality of ESL reading textbooks has improved dramatically in recent years, the process of selecting an appropriate text has not become any easier for most teachers and administrators. The textbook selection process often gravitates to one of two extremes. In the process of evaluating textbooks, some educators ask so many questions that they are never able to complete the process. Others choose a reading textbook with little or no evaluation, yet it becomes the centerpiece of the curriculum until another haphazardly chosen reader replaces it. The paper discusses for evaluating reading textbooks for use in ESL/EFL classrooms. Classroom teachers spend much 
time using textbooks in class, so choosing an appropriate one is important. And the paper describes the role of the textbook. Using this will make the textbook selection process more efficient and more reliable.

\section{The Role of the Textbook in the English Classroom}

Zeng \& Takatsuka (2009) investigates EFL learners' dialogues in synchronous task-based computer-mediated communication (CMC). The focus is on whether learners engage each other in text-based dialogues regarding the language use in pursuit of the task goal in the CMC context and how their mutual engagement impacts their language learning. The findings revealed that learners did assist each other in attending to language forms through collaborative dialogue, which consequently enhanced their language learning. Yasemin (2009) discusses an evaluation of the three English textbooks which have been prescribed for use in grade 4 classes by the Turkish Ministry of National Education in state primary schools. Teachers and students responded to a 37-item textbook evaluation scheme (Smiley Questionnaire) to express their perceptions concerning various aspects of the textbooks. Both groups of participants were also interviewed to gain further insights into the use of the textbooks. Findings revealed the extent of appropriateness of the three textbooks used by young learners of English. Suggestions are offered for the future revision and/or designing the textbooks for young learners of English. According to Sznajder (2010) research, while most scholars agree that metaphors should be included in English for Specific Purposes (ESP) syllabuses as a potentially problematic area in successful language learning, it is still not entirely clear which metaphors should be taught. In this study, metaphorical words and phrases from the aforementioned business English textbook were contrasted with the metaphors identified in a sample of the corpus of business periodical and journal articles. These findings suggest that the corpus evidence, including frequency data, should be considered when selecting teachable metaphorical material for business English instruction. Other corpus data related to metaphor collocational patterns and to the preference in the choice of metaphorical synonyms further confirm the need to base the selection of metaphors for classroom instruction on real language use.

According to Chen (2008), Information and communication technology has affected language instruction in Taiwanese higher education. Both quantitative and qualitative results show that teacher training is crucial for Internet-integration instruction by the teachers of English as a foreign language (EFL) in Northern Taiwanese higher education institutions. Continuous professional development focused on technology application in language instruction is imperative. Richards, Tung \& Ng (1992) reported that English teachers in Hong Kong held a set of relatively consistent beliefs relating to such issues as the nature of the ESL curriculum, the role of English in society, the relevance of theory to practice, the teachers' role in the classroom, and others. Sheldon (1988) has offered several other reasons for textbook evaluation. He suggests that the selection of an ELT textbook often signals an important administrative and educational decision in which there is considerable professional, financial, or even political investment. A thorough evaluation, therefore, would enable the managerial and teaching staff of a specific institution or organization to discriminate between all of the available textbooks on the market (David, 2001).

In Ruben (2010) research, a content analysis of the textbooks used in the Dutch early childhood teacher education shows clear inconsistencies with the intended curriculum. Neither the content standards found in the professional profile for teachers nor the content standards from the educational profile of their training courses are adequately covered in the books. Whilst they pay considerable attention to the teacher's educational duties, other tasks outside the primary work process are either dealt with in much less detail or ignored altogether, including the need for strategic planning, for reflection and evaluation, for the development of educational policy, and for co-operation and liaison with colleagues from other disciplines. Marc and Kees (2009) analyze the content of textbooks as well as teachers' usage of them. Results show author representation in textbooks increasingly resembles students' reading preferences at the expense of selections made by literary experts. At the same time, teachers have increasingly adopted textbooks that regarded students' preferences the most. These trends seem to be the result of changes in the student population rather than teachers' professional characteristics.

Research indicates that EFL textbooks are used in many different ways, depending on a wide spectrum of factors. The teacher seems to be the most important factor. In a number of scholarly publications, including some introductory books to teaching English as a foreign language, different preferences or styles of textbook use are identified and described in more or less detail (Haß, 2006), ranging from complete textbook-reliance to more selective approaches, from the eclectic use of many different instructional resources to the employment of self-made materials, especially in project-oriented or project-based sequences of instruction. In this context, textbook-bound teaching is often set in opposition to more flexible approaches to textbook use. The latter is often seen as the most adequate, convincing and appropriate.

\section{English Textbook in Teaching and Learning}

Textbooks remain a staple within school curricula worldwide, presenting teachers and students with the official knowledge of school subjects as well as the preferred values, attitudes, skills, and behaviors of experts in those 
fields. Textbooks are commodities, political objects, and cultural representations and, therefore, are the site and result of struggles and compromise in order to determine how and by whom they will be produced, how and by whom their contents will be selected, how and to whom they will be distributed, and how teachers and students will make use of them(Shannon, 2010). The integration of language and content instruction is of increasing interest in second and foreign language programs at elementary, secondary, and tertiary levels around the world (Short, 2006). Joan (2001) presents research on the potential of four intermediate-level ESL grammar textbooks to provide student control of learning, based on the textbook authors' presentation of student decision making opportunities in tasks. Textbook tasks were analyzed for the potential controller of learning conditions related to content choice, procedure options, and evaluation techniques, based on the studies of Grannis. The findings suggest that students potentially have few choices and thus little control of the educational process. The majority of tasks may train students primarily for bureaucratic jobs while the focus on right answers may impede language learning. ESL teachers need to mediate a textbook's potential to control if the goal is to create learners who have some control over their own learning through curricular decision making. According to Cortazzi and Jin (1999), the textbook can be a teacher, a map, a resource, a trainer, an authority, and an ideology. Hence, the textbook can be a major source of cultural elements besides providing linguistic and topical contents which necessarily reflect the ideology inherent in the ESL context of a particular circle.

According to Feryok (2008), previous studies have shown that teacher cognitions and practices can be inconsistent, particularly with claims about communicative teaching practices. Analysis of the interview data shows that the teacher articulated a cohesive, coherent practical theory. The observation showed that she implemented many of her stated cognitions; however, some cognition appeared to diverge in practice. Both her cognitions and practices were influenced by her understanding of the context in which she worked; meeting different expectations in particular may have contributed to the divergence between cognitions and practices. Inceçay \& Inceçay (2009) investigates the perceptions of 30 Turkish university students in order to better understand the appropriateness and effectiveness of communicative and non-communicative activities in their English as a foreign language (EFL) courses in a private university preparatory school in Istanbul, Turkey. Using multi-method, data were collected by means of a questionnaire and semi-structured interview. Quantitative data were supported by the qualitative data to provide more reliable results. The results suggest that, EFL countries like Turkey need to modernize and update their teaching methods which means doing changes by taking students' previous educational habits into consideration. It is obvious from the study that students in non-English speaking countries make use of communicative language teaching (CLT) if communicative activities and non-communicative activities are combined in English classrooms.

The attributing of the textbook as a direct cause of learning or teaching failure is superficial, given that even a strict adherence to a well-constructed textbook requires as much mastery in teaching as one's ability to employ flexible and creative teaching techniques after fully integrating its contents and structure. The teacher-textbook model is more accurately conceptualized as a constant upward trend of improvements in teaching skills that levels off at a threshold, after which teaching skills can only stagnate or improve. Skill-building and gradual mastery is expected of any skill when exercised constantly, yet novel advances occur only with individual potential or circumstances with fewer limiting factors; the textbook, in this sense, is a mediating effect which determines how quickly teachers can achieve a threshold of standardized teaching, and how much room there is for teaching flexibility and creativity once textbook training is complete. A well-constructed textbook should present not only language content that is communicable and interactive to the student, but also form a framework from which adequate teacher improvisation and teaching flexibility can develop and gradually improve. Determining how feasible or appropriate the use of one or more commercial textbook is in terms of satisfying learning objectives and the teacher/student relationship in the classroom would be the first step in preventing poor teaching and learning quality. When used effectively, authentic materials help bring the real world into the classroom and significantly enliven the ESL class. Exposing the students to cultural features generates a deeper understanding of and interest in the topic. On one hand, the students develop their ability to zero in on relevant information, and on the other, they learn how to disregard what is not relevant. As students pool their individual strengths they gain confidence in being able to function in an English-speaking society (Kelly, Lawrence, Mark \& Bruce, 2002).

\section{English Textbook Selection and Evaluation}

The reliability of selecting and evaluating a commercial textbook is influenced by the target use group, the perspective used in making the selection and the instruments used in the process (Gall, 1981). According to Hutchinson and Waters (1987), textbook evaluation is basically a straightforward, analytical matching process: matching needs to available solutions. Though providing food for thought, checklists and questionnaires like these have probably had little real influence on textbook evaluation in terms of either ELT reviewing practice or educational decision making. Perhaps they have simply not had the currency they deserve, most teachers, at any rate, 
being unaware that they even exist. Finding back issues of relevant journals in many teaching contexts (and indeed in some ELT libraries) is also very difficult (Sheldon, 1988).

In some situations, the textbook may function as a supplement to the teachers' instruction in the ESL teaching and learning process. For most teachers, textbooks provide the foundation for the content of lessons, the balance of the skills taught, as well as the kinds of language practice the students engage in during class activities. For the ESL learners, the textbook becomes the major source of contact they have with the language apart from the input provided by the teacher. Prior to selecting a textbook, educators should thoroughly examine the program curriculum. If the goals and curriculum of the program are clear and well defined, the parallels with certain textbooks may become obvious. For example, if one of the goals of the program is to give students an opportunity to interact with authentic texts, then books that use articles written for native English speakers would be appropriate. If the program focuses on developing reading fluency, books designed to support the development of reading skills would be appropriate. According to Gretchen (2003) research, the textbook has a process for developing curriculum that is based on a needs assessment of learners and includes participation and input from other stakeholders. The curriculum and instructional materials are easily accessible, up to date, appropriate for learners, culturally sensitive, oriented to the language and literacy needs of the learners, and suitable for a variety of learning styles. Sample Measures for Instructional Materials:

They are up to date (e.g. published within the past 10 years).

They contain relevant content.

They take into account the linguistic and cultural diversity of the student population.

The layout and formatting (including font size) is appropriate for the student population.

Visuals and graphics are clear, appropriate for adults and culturally sensitive.

Voice and sound in audiovisual materials are clear, authentic, and appropriate.

The materials address a variety of learning styles.

The materials are conducive to being used with a variety of grouping strategies.

The materials contain exercises in which learners share previous experience with prior knowledge of the content.

Evaluates the role of commercially available foreign language teaching materials, citing the reasons for using these materials as time pressure on teachers, the uncertain language competence of teachers; the materials' visual appeal to students; and the need of a yardstick of progress (Roberts, 1999).Jiang (2006) describes the linguistic forms used to perform the speech act of suggestions in both real language and ESL textbooks. Comparisons between suggestions in two authentic settings in a corpus, professor-student interaction during office hours and student-student study groups, and six popular ESL textbooks, three old and three recent, were made to evaluate the extent to which textbook materials reflect real-life language use. Register differences between office hours and study groups demonstrate the contextual sensitivity of certain linguistic forms and the complexity of performing speech acts. Although the new generation textbooks introduce more linguistic structures for suggestions than the old generation textbooks, the discrepancies between real language use and ESL textbooks are still apparent. According to Los Angeles Unified School District Textbook Evaluation (2002) research, the following model standards, current teaching strategies and methods are used to rate textbook effectiveness:

Integrates four language skills: speaking, listening, reading, writing.

Incorporates life skills included in course outline.

Receptive skills before productive (listen/read before speak/write).

Integrates different learning styles: aural, oral, visual, kinesthetic.

Incorporates and varies different methodologies and techniques.

Grouping strategies: individual, pair, group and team work.

Incorporates higher level thinking skills and problem solving.

Sufficient student practice.

Grammar: taught in context; spiraling activities.

Interactive/communicative approaches.

Vocabulary: target vocabulary in lesson, recycled in lesson. 
Reading: pre-read, read, post-read activities; theme recycled.

Writing activities integrated in text.

Assessments and self evaluations at end of unit; final tests.

Design and Format: illustrations, type size, color/black white, layout.

Pace appropriate to level.

Promotes cross-cultural awareness.

In this case, Burden (2008) findings suggest that even if the evaluation is intended for formative development, many teachers do not gain any new knowledge as they question both the value of the information received and the overall content validity of evaluations as they are cross-curricular and used in all courses. Evaluation should draw distinction between prescriptive, contextual, summative evaluation and collaborative approaches that show the richness and diversity of teaching while giving learners as well as ELT teachers more voice.

\section{Conclusions}

This study to discuss a textbook evaluation checklist for standardized use at the elementary level, based on a meta-analysis of checklists published internationally and locally. It is expected that the advent of an official, standardized textbook checklist capable of both predictive and retrospective evaluation of the textbook itself, and its pedagogical implications on teaching skills, and classroom dynamics, would become critical amidst the growing number of commercial textbooks available for selection at the elementary level. Decisions related to textbook selection will affect teachers, students, and the overall classroom dynamic. It is probably one of the most important decisions facing ESL educators. Teachers should be able to respond to these new challenges and changes by altering activities and creating the more tailored ones. The use of an evaluation procedure or checklist can lead to a more systematic and thorough examination of potential textbooks and to enhanced outcomes for learners, instructors, and administrators. The textbook is a tool, and the teacher must know not only how to use it, but how useful it can be.

\section{References}

Parrish, Betsy (2004).Teaching Adult ESL A Practical Introduction, McGraw Hill: New York, NY.

Zeng, G., \& Takatsuka, S. (2009). Text-based peer-peer collaborative dialogue in a computer-mediated learning environment in the EFL context. System, 37, p434-446.

Yasemin K. ( 2009) .Evaluating the English textbooks for young learners of English at Turkish primary education, Procedia - Social and Behavioral Sciences, 1(1), p79-83.

Hanna Skorczynska Sznajder (2009). A corpus-based evaluation of metaphors in a business English textbook. English for Specific Purposes, 29(1), p30-42.

Ruben G. Fukkink (2010). Missing pages? A study of textbooks for Dutch early childhood teacher education. Teaching and Teacher Education. 26(3), p371-376.

Marc V., \& Rees, K. V. (2009). Literary education curriculum and institutional contexts: Textbook content and teachers' textbook usage in Dutch literary education, 1968-2000. Poetics, 37(1), p74-97.

Haß, F. (Hrsg.) (2006). Fachdidaktik Englisch. Tradition Innovation Praxis. Stuttgart: Klett.

P. Shannon (2010). Textbook Development and Selection. International Encyclopedia of Education (Third Edition), p397-402.

D.J. Short (2006). Content Teaching and Learning and Language. Encyclopedia of Language \& Linguistics (Second Edition), p101-105.

Joan Lesikin (2001). Potential Student Decision Making in Academic ESL Grammar Textbooks. Linguistics and Education, 12(1), p25-49.

Cortazzi, M.,\& Jin, L. (1999). Cultural Mirrors, Materials and methods in the EFL classroom. In E.Hinkel (Ed.), Culture in Second Language Teaching and Learning. Cambridge University Press: USA.

Charles Kelly, Lawrence Kelly, Mark Offner and Bruce Vorland (2002). Effective Ways to Use Authentic Materials with ESL/EFL Students.The Internet TESL Journal, 7(11).

Litaz, David (2001) TEXTBOOK EVALUATION AND ELT MANAGEMENT: A SOUTH KOREAN CASE STUDY. Asian EFL Journal. http://www.asian-efl-journal.com/Litz_thesis.pdf

Yu-Li Chen (2008). A mixed-method study of EFL teachers' Internet use in language instruction. Teaching and Teacher Education, 24(4), p1015-1028. 
Bitterlin, Gretchen (2003). TESOL Standards for Adult Education ESL Programs. TESOL: Alexandria,Virginia.

J. T. Roberts (1999). Demystifying materials evaluation. System. 24(3), p375-389.

Xiangying Jiang (2006). Suggestions: What should ESL students know? System. 34(1), p36-54.

ESL/CBET and Citizenship Programs, Division of Adult and Career Education, Los Angeles Unified School District 2002.

Peter Burden (2008). ELT teacher views on the appropriateness for teacher development of end of semester student evaluation of teaching in a Japanese context. System. 36(3), p478-491.

Richards, J. C., Tung, P., \& Ng, P. (1992). The culture of the English language teacher: A Hong Kong example. RELC Journal, 23 (1), p81-103.

Sheldon, Leslie E. (1988). Evaluating ELT textbooks and materials. ELT Journal, 42 (4), 237-246.

Feryok, A. (2008). An Armenian English language teacher's practical theory of communicative language teaching. System, 36(2), 227-240.

Incecay, G., \& Incecay, V. (2009). Turkish university students' perceptions of communicative and non-communicative activities in EFL classroom. Procedia Social and Behavioral Sciences, 1, 618-622.

Gall, M.D (1981). Handbook for evaluating and selecting curriculum materials. Oregon: University of Oregon.

Hutchinson, T. and A. Waters. (1987). English For Specific Purposes: A Learning-Centred Approach. Cambridge: Cambridge University Press. 